\section{BOOK REVIEW}

Infectious Diseases of the Fetus and Newborn Infant. Third Edition. Edited by Jack S Remington and Jerome $\mathrm{O}$ Klein. (Pp 1122; £132.50 hardback.) W B Saunders Company (Harcourt Brace Jovanovich), 1990. ISBN 0-7216-2434-0.

I pleaded with the editors to be asked to review this book, even bargaining that I would agree to write an annotation on condition that I be allowed to review it. When I was first consulted on neonatal infections, Remington and Klein was a combination of Bible and 'suck rag', the all knowing comfort. It is a tour de force. The arrival of the third edition on my desk gave me an enormous thrill.

I was not disappointed. The book has been extensively updated, and every chapter contains references up to 1987 or 1988 . There are new chapters on breast milk and on human immunodeficiency virus infection. Some chapters have new authors, and in almost al cases they are recognised leaders in their field. Major revisions have been made, encompassing technical advances, to the chapters on immunology (Christopher Wilson), cytomegalovirus (Sergio Stagno), herpes simplex virus (Richard Whitley), and obstetric factors (Ronald Gibbs): all are new authors in this book and their chapters are fresh and informative.

This edition is more practical than the previous two editions. For example, previously the recommendations for the management of illnesses like perinatal chickenpox and perinatal tuberculosis tended to be unreasonable and didactic ('separate mother and child, keep siblings away, and discharge home after two weeks') whereas they are now more humane and workable. Guidelines on the management of the baby whose mother has gestational syphilis are clear and practicable. I tried a few topical issues to see if they were covered: ureaplasma is thoughtfully discussed by Jerry Klein, human herpesvirus 6 is mentioned, hepatitis $C$ virus caught the stop press. Imipenem and aztreonam are covered in the chapter on antibiotics. Surprisingly, there is virtually no mention of the use of intravenous immunoglobulins to prevent or treat neonatal infections.

This is an exhaustive book; there are at least 200 references for most chapters and 792 in the chapter on group B streptococcal infections. At times it is exhausting. The chapter on toxoplasmosis is still over 100 pages long and could have been shortened by half without substantial loss of content. But that weakness is also the book's strength. It is an invaluable reference book covering almost every aspect of neonatal infection, and is accessibly presented so that information can easily be found. Photographs are good, although graphics are underused.

I must not be churlish. No book is perfect, but this is as close to it as any medical reference book I know. All neonatologists need access to this book, which contains so much information not readily available elsewhere. There is enough new material since the second edition in 1983 to suggest you dig deep in your pockets (though not desperately deep by modern standards) and buy this excellent book.

DAVID ISAACS Consultant paediatrician

\title{
Chromosomes galore
}

A fascinating review in Developmental Medicine and Child Neurology (Punnett and Zakai 1990;32:824-9) covers the chromosomal origins of nine syndromes. The syndromes that will be most familiar to paediatricians are the Prader-Willi, Angelman (happy puppet), DiGeorge, and Beckwith-Wiedemann. The first two of these are apparently caused by deletion of the same gene from the long arm of chromosome $15\left(15 \mathrm{ql1}^{-}\right)$. How come? Well it seems that if the missing bit is of paternal original you get Prader-Willi syndrome and if it's from the mother you have Angelman's syndrome. Neat, isn't it? The phenomenon of differential expression of apparently identical genetic material is called imprinting.

DiGeorge's syndrome, it seems, is associated with abnormalities of several chromosomes, including the long arm of chromosome 22 (22q11), and the short arms of chromosomes 10 (10p13) and 17 (17p13).

Beckwith-Wiedemann syndrome is associated occasionally with a visible duplication within the short arm of chromosome 11 (11p15). Family studies have indicated tight linkage to markers at 11p15, though DNA analysis has so far failed to demonstrate increased gene dosage at that site. Curiously all monozygotic twins with this syndrome have been girls and their twin sisters have been normal.

Alagille's syndrome (intrahepatic biliary hypoplasia, characteristic facies, mental retardation, and heart and vertebral defects) is associated with a deletion on the short arm of chromosome 20 (20p11).

The other syndromes are ones I haven't come across beforeMiller-Dieker, Langer-Giedion, and Pallister-Killian, and the AGR triad. The Pallister-Killian syndrome is associated with a duplication (12p) and the others with microdeletions (17p, 8q, 11p).

The geneticist is king! Read Francis Crick's autobiography for an insight into how it all started. ${ }^{1}$ 